\title{
GPPS-CH-2020-43
}

\section{DEVELOPMENT OF A RESEARCH MODEL TO STUDY THE OPERABILITY OF A VARIABLE PITCH FAN AERO ENGINE IN REVERSE THRUST}

\author{
David John Rajendran \\ Cranfield University \\ Cranfield, United Kingdom
}

\author{
David Bentley \\ Cranfield University \\ Cranfield, United Kingdom
}

\author{
Hasani Azamar Aguirre \\ Cranfield University \\ Cranfield, United Kingdom
}

\author{
Richard Tunstall \\ Rolls-Royce plc. \\ Bristol, United Kingdom
}

\author{
Vassilios Pachidis \\ Cranfield University \\ Cranfield, United Kingdom
}

\begin{abstract}
A rationale for the level of model fidelity required to provide the most representative flow field information to ascertain the feasibility of using a Variable Pitch Fan (VPF) in a modern high bypass ratio aero engine to generate reverse thrust is described in this paper. This is done by comparing the 3D RANS flow field solution for a newly developed reverse flow VPF design from two research models: i) isolated engine model in which the bypass duct, guide vanes, splitter and VPF are wrapped in an axisymmetric nacelle and placed in a generic far-field domain and b) integrated model in which the engine is installed to an airframe in landing configuration through a pylon and placed in a far-field domain bound by a rolling runway. The flow field solution obtained at an aircraft landing speed of $80 \mathrm{knots}$ indicates that even though both models can predict the general flow patterns, there are substantial differences in parameters such as the amount of reverse stream, circumferential distribution of flow properties and flow development downstream of the engine. These differences impact the levels of reverse thrust generated, flow distortion entering the core engine and resultant airframe forces. This study makes the case that it is necessary to use an integrated model that includes a full engine nacelle installed on an airframe, to answer design questions for engineering the VPF system to generate reverse thrust.
\end{abstract}

\section{INTRODUCTION}

Modern ultra-high bypass ratio civil gas turbine engines have bypass ratios in the range of $10-14$ to increase engine propulsive efficiency. The fan stage in such high bypass ratio engines is susceptible to aerodynamic instabilities at offdesign conditions due to low design fan pressure ratios dictated by engine thermodynamic cycle requirements. The VPF with variable stagger angle fan blades can be used to avoid such unstable operating regimes and optimise fan operation without resorting to a variable area bypass nozzle. The variable area nozzle for high bypass ratio engines tend to be complex and heavy enough to offset the advantages obtained from high bypass ratios. Therefore, the VPF with lighter actuation systems in the fan spinner is a more viable design alternative. A number of comparative studies between the VPF and the variable area nozzle note that the VPF can provide up to $7 \%$ improvement in the aircraft mission fuel burn (Denning, 1972; Halliwell and Justice, 2012; Mazzawy, 2012; Krishnan et al, 2013; Yang and Tang, 2018).

The direction of airflow through the VPF can be reversed if the blade aerofoils are rotated by $90^{\circ}$ in the clockwise or anti-clockwise direction (Moore and Osborn, 1979). Therefore, the VPF can be used to generate reverse thrust by causing flow to be sucked in from the bypass nozzle exit and ejected through the fan inlet. The bulky nacelle based cascade thrust reverse unit can be eliminated when the VPF is used for reverse thrust. Shorter 'slim-line' nacelles that reduce installation drag and aircraft weight can then be designed without the constraint of housing the thrust reverser cascades (Hamilton and Welge, 1992).

The concept of using a VPF system to generate reverse thrust has been demonstrated by the NASA Advanced Ducted Propulsor (ADP) and Quiet Clean Short-haul Experimental Engine (QCSEE) programs. A number of VPF designs with optimized performance in different portions of the aircraft mission profile and the capability to induce reverse flow were developed. Detailed exploration of the behaviour of one such VPF design was carried out in both 
wind-tunnels and outdoor test rigs. The configuration tested in the wind tunnel and the outdoor test rig consisted of the reverse stream flow path from a representative bypass nozzle exit, splitter into the core engine and the VPF in reverse thrust: all wrapped in a generic nacelle. The results from the test campaign were presented in terms of the flow parameter profiles at different span-wise locations and the force balance readings in static stand-alone conditions. A large number of transient studies were also conducted to understand the transition of the VPF from the forward nominal operating condition to the reverse flow condition (Schaefer et al, 1977; Reemsnyder and Sagerser, 1979; Samanich et al, 1980).

The flow field for one of the ADP designs in the test rig was described in a computational study by Tweedt. The computational domain consisted of the reverse stream flow path in a nacelle as used in the test rig. The results were reported in terms of the flow field variables in three different nominal forward flow VPF settings (Tweedt, 2014). This study was extended in a recent computational exploration by Williams and Hall. A similar computational model was used with the VPF set in different reverse flow stagger angle settings. The resultant general flow field when the VPF is operating in reverse thrust was reported and preliminary estimation of the levels of reverse thrust generated was carried out. The findings from this computational study was similar to the general flow field behaviour observed from the ADP experiments (Williams and Hall, 2018).

The models used in the experimental and computational studies to date include only the engine reverse stream flow path in a generic nacelle. These models were used to prove the potential of the VPF system to generate thrust and to describe the general reverse thrust flow field. However, if a VPF system is to be used in an aircraft to generate reverse thrust and replace the conventional thrust reversers, it is required to carry out a study from an aircraft-engine design and integration perspective. It is to be expected that the flow field of the reverse thrust VPF will be different when the engine is integrated to the airframe in the vicinity of the rolling runway during the aircraft landing run.

Therefore, a key decision to be made before undertaking such a design study is to determine the level of modelling fidelity required to appropriately answer design questions of interest. This is because a realistic representation of the reverse thrust VPF flow field in a target airframe is necessary to estimate the reverse thrust levels achievable and to ensure stable operation of the engine. Can this realistic flow field description be obtained from a traditional modelling approach with only the isolated engine or does it require the development of an integrated model with the engine installed to a representative airframe? This is answered in the present study in which a VPF design for a modern high bypass ratio engine is integrated into two different models - a representative typical isolated stand-alone engine model and another detailed integrated model with the engine installed to the airframe. The differences in the flow field solution between the two models are discussed in detail to provide a rationale for using the integrated model to study the feasibility of using VPF to generate reverse thrust.

\section{METHODOLOGY}

The objective of this study is to delineate the importance of an integrated modelling approach in which the engine is installed to an airframe as compared to the traditional isolated engine modelling approach to study the VPF reverse thrust flow field (Tweedt, 2014; Williams and Hall, 2018). To achieve this objective, it is necessary to develop a new VPF design for a representative future high bypass ratio engine where the system is likely to be implemented. The engine considered in the study is a $40000 \mathrm{lbf}$ two-spool geared turbofan configuration with a bypass ratio of 14 at design point. The VPF design is then assembled into the isolated and integrated engine models. The details of the VPF design and the subsequent development into the isolated and the integrated engine models is described in this section.

\section{VPF Design}

The design point $1 \mathrm{D}$ engine thermodynamic cycle parameters for the VPF in forward flow are shown in Table 1 (Mourouzidis, 2016). The 2D meridional flow path design for the VPF stage that meets the thermodynamic performance, preliminary stress and life requirements is generated in ATLAS, a Cranfield University in-house full engine flow path design and weight estimation tool (Lolis et al, 2014). The 2D gas flow path for the entire engine as shown in Figure 1 is generated because it is required to appropriately resolve the reverse stream development.

\begin{tabular}{|c|c|}
\hline \multicolumn{2}{|c|}{$\begin{array}{c}\text { Table } 1 \\
\text { VPF Design Parameters at Design Point }\end{array}$} \\
\hline Parameter & Value \\
\hline Inlet Mach Number & 0.6 \\
\hline Fan Outer Pressure Ratio & 1.3 \\
\hline Fan Inner Pressure Ratio & 1.1 \\
\hline Hub to tip ratio & 0.3 \\
\hline
\end{tabular}




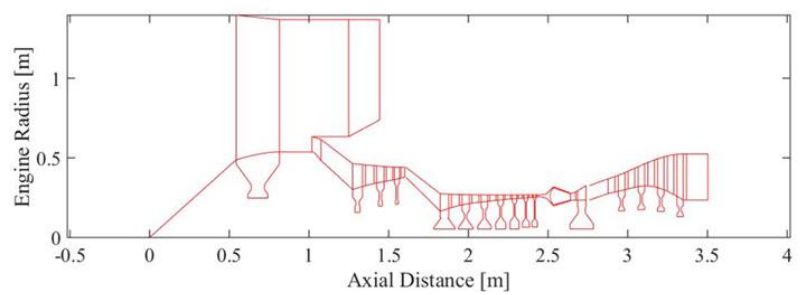

Figure 12D gas flow path for the two-spool geared turbofan engine obtained from ATLAS

The 3D VPF blade aerofoil design has to operate satisfactorily in both forward and reverse flow. Therefore, it is decided to develop the 3D design for the present engine from the aerofoil design that was tested and validated in both forward and reverse flow in the NASA ADP program (Schaefer et al, 1977). The ADP design is a rig configuration with a maximum diameter of 22 inches and with a hub-to-tip ratio of 0.42 . The ADP rig design is scaled to 110 inches engine inlet diameter and extrapolated to 0.3 hub-to-tip ratio using SOCRATES (Templalexis et al, 2006), another in-house stream-line curvature based through flow design code, as shown in Figure 2. The aerodynamic performance of the scaled VPF is tested using SOCRATES in different forward flow pitch settings. Thereafter, minor modifications in the flow angles and thickness distributions in the extrapolated regions are carried out to ensure that the design meets the thermodynamic cycle requirements. Other than the changes in the hub-to-tip ratio and the profile changes in the extrapolated regions, other fan design parameters like pressure ratio, tip speed and loading distribution are the same as in the baseline validated ADP design. The ability of the 3D blade aerofoils to change the direction of airflow when it is rotated by $90^{\circ}$ through the feather pitch is verified by a 3D RANS solution of the rotated fan stage. The blade section views at three span-wise locations of the fan in reverse flow setting is shown in Figure 3.

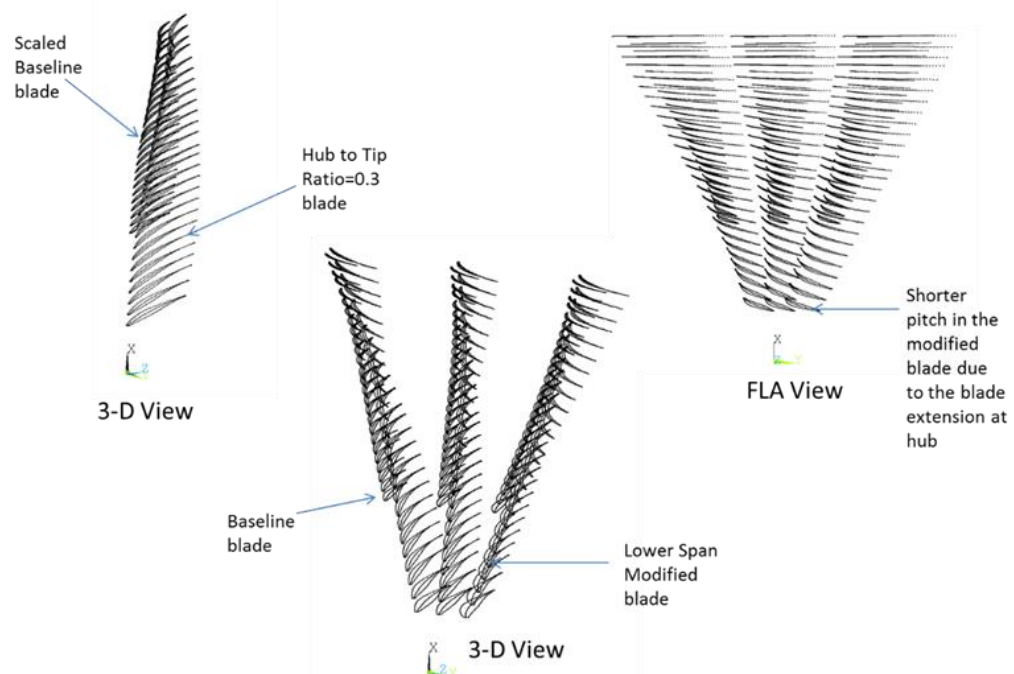

Figure 2 Evolution of fan design from scaled baseline

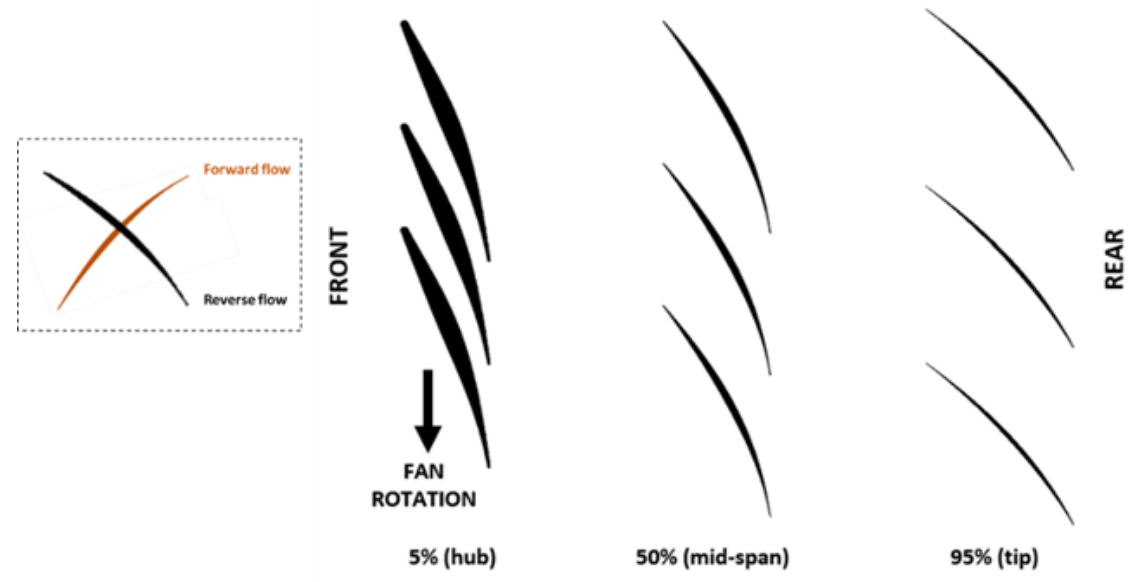

Figure 3 Evolution of fan design from scaled baseline 
The Outlet Guide Vane (OGV) is also scaled to the required dimensions from the ADP baseline. The VPF in reverse thrust setting is then assembled into the isolated and integrated models as described below.

\section{Isolated Research Model}

The isolated model is defined to capture the development of the reverse stream from the bypass nozzle exit to the fan inlet plane as in the NASA experiments and subsequent computational studies. This includes the bypass nozzle duct, OGV, splitter into the core engine and the VPF. A portion of the core engine exhaust duct is also modelled to check for hot air ingestion during flow reversal. All the internal flow path components are full annular $360^{\circ}$ representations to capture the flow development and to quantify the flow distortion into the core engine. A representative nacelle is designed using GEMINI, a Cranfield in-house nacelle design tool. The development of the nacelle from the 2D meridional flow path and subsequent placement of detailed VPF and OGV 3D designs is shown in Figure 4. The engine is then placed in a generic far field domain to define the isolated research model as shown in Figure 5.
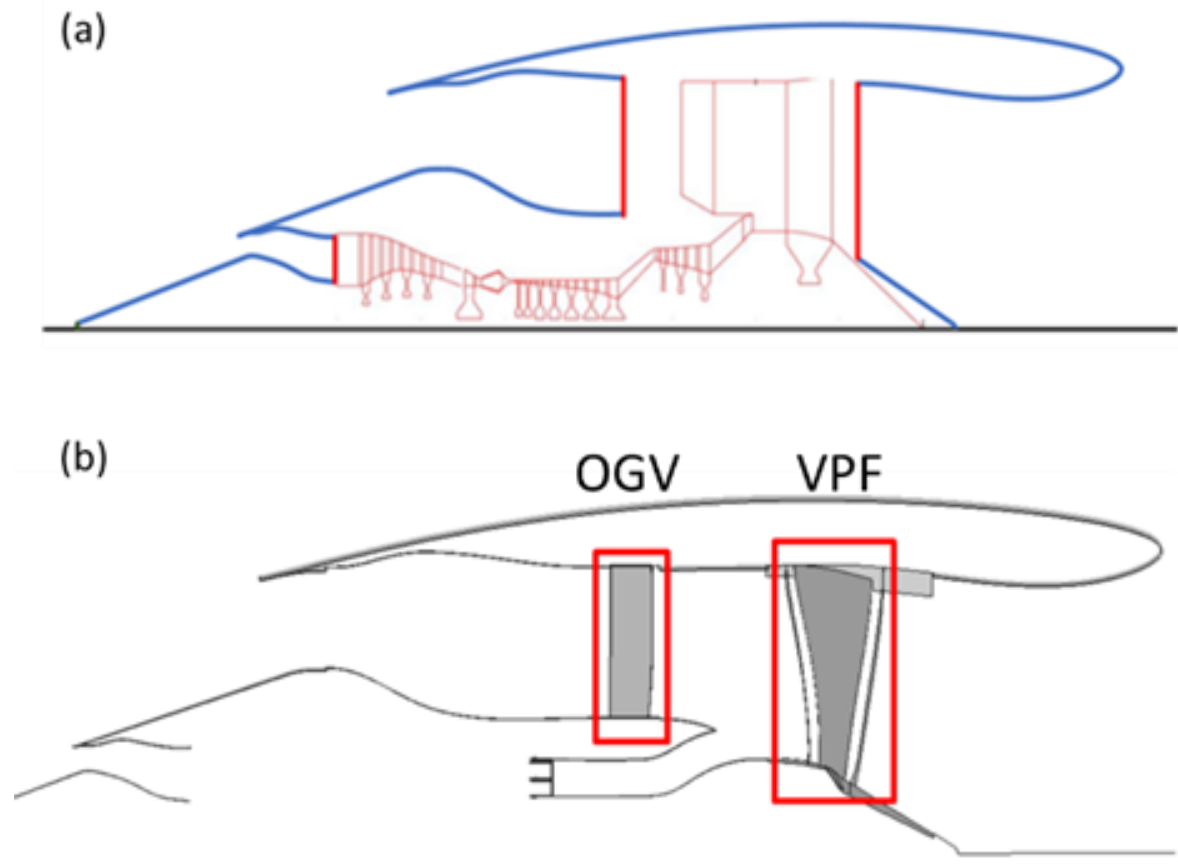

Figure 4 - (a) Nacelle design with the flow path - red lines show interface planes. (b) Placement of 3D designs of VPF and OGV in flow path

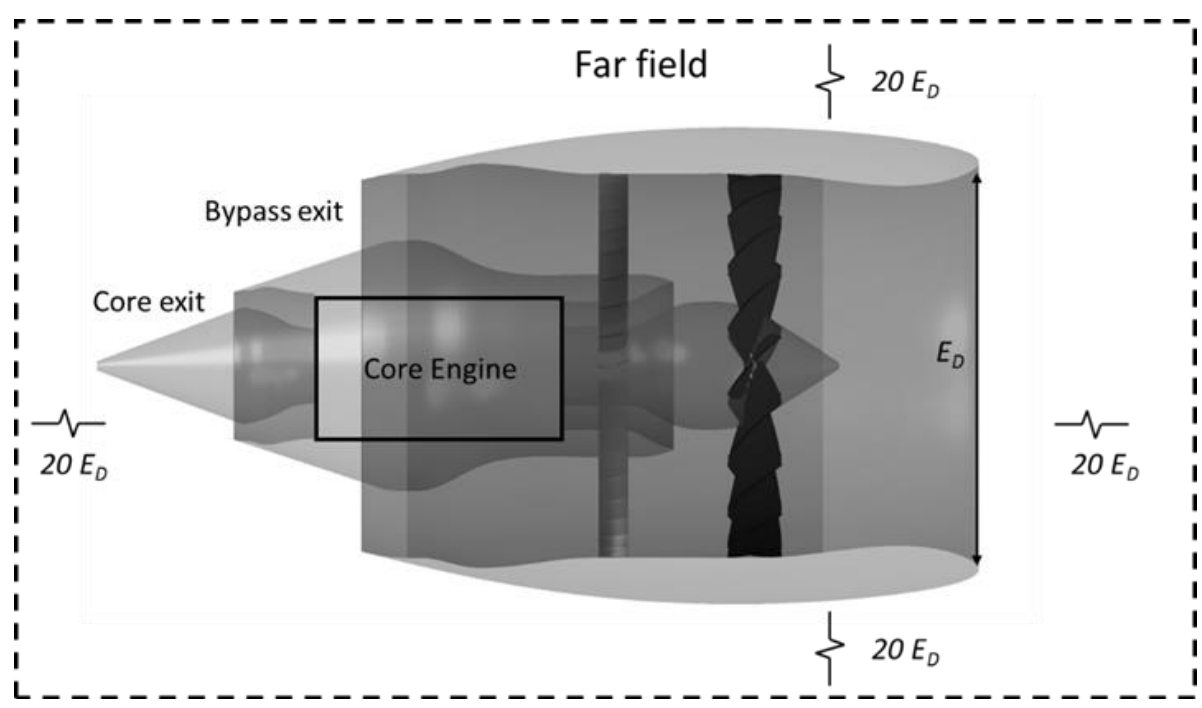

Figure 5 Isolated research model in far field domain 


\section{Integrated Research Model}

The same engine as in the isolated model is attached to an airframe through a pylon and placed in a far-field domain bound by a ground plane to define the integrated research model. The airframe is a scaled DLR F11 airframe, with flaps, slats and spoilers deployed in landing configuration. The scaling factor is computed to match the wingspan of a target airframe that uses two $40000 \mathrm{lbf}$ engines. The development of the airframe model with the high lift surfaces is shown schematically in Figure 6. The pylon is defined using symmetric NACA profiles and attached to the airframe with a ground clearance of $0.6 \mathrm{~m}$. The bypass nozzle area is corrected to accommodate the reduction in area caused by the pylon strut. A symmetric half of the airframe with one engine is considered for the model definition as shown in Figure 7. Further details of the VPF design and the components of the integrated research model are described in Ref. (Bentley, 2018; Rajendran and Pachidis, 2019).

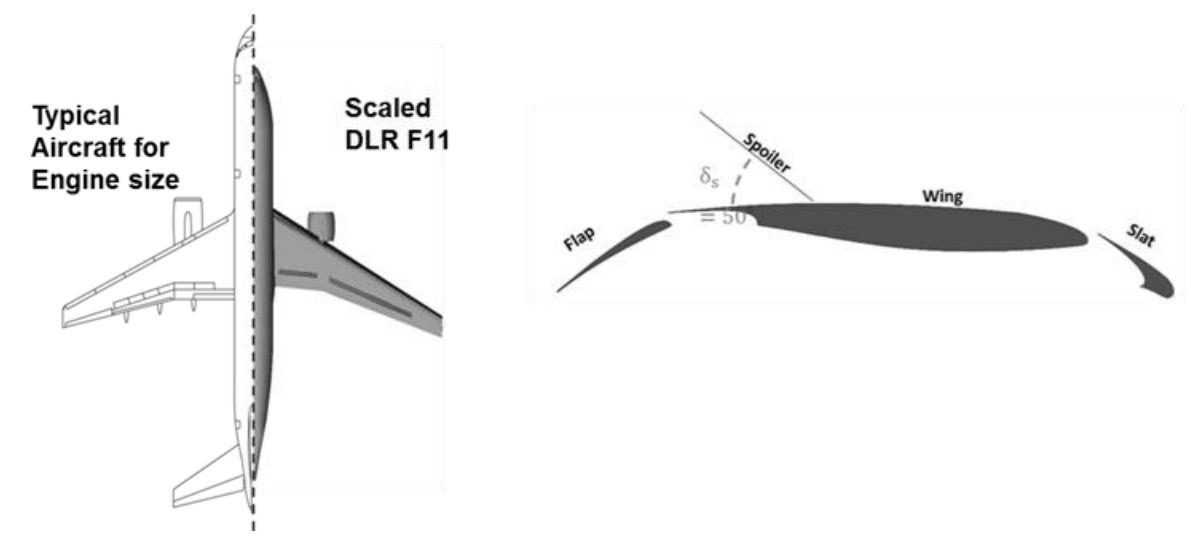

Figure 6 Development of airframe with flaps, slats and spoilers

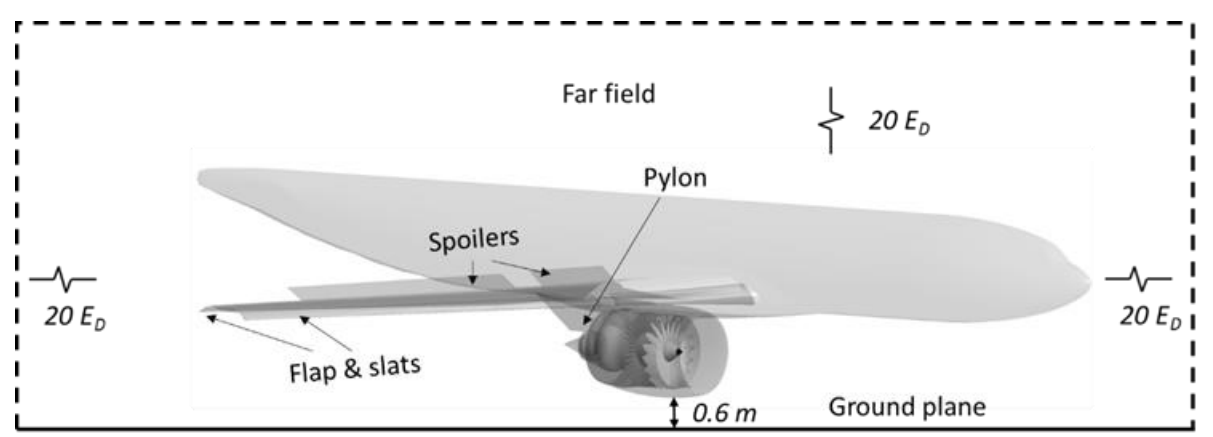

\section{Figure 7 Integrated research model with far field domain bound by ground plane (Rajendran and Pachidis, 2019)}

\section{Model Grid Generation}

The computational models are built in modular assemblies to enable separate grid generation and to aid use of same grids for common components. In the engine internal flow path, the VPF, splitter and core exhaust domains are common to both models. The OGV domain in the isolated model is extended till the bypass nozzle exit. However, in the integrated model, the OGV domain ends at half upstream axial chord because of the need to accommodate the pylon strut. Multiblock structured grids with $\mathrm{H} / \mathrm{J}$-grid topology are used to discretize the VPF and OGV turbomachinery domains in both models. O-grid blocks are used around the blade aerofoils with y+ less than 1 to resolve the boundary layer flow physics. The splitter and core exhaust domain discretization are carried out by first generating a 2D blocking structure with grid elements clustered near the wall surfaces and thereafter revolving the 2D grid around the engine axis to obtain the final 3D grid. Unstructured elements are used to discretize the pylon strut in the bypass nozzle duct because there are no bounded aerofoil passages to guide flow aligned grid generation. Representative grids of the engine internal flow path components are shown in Figure 8. The separate grids of the internal components are joined at interface planes to define the complete $3 \mathrm{D}$ engine flow path.

The far-field external domain of the isolated model is defined by the nacelle and far-field boundaries. A 2D structured grid with near nacelle wall elements having $y+$ less than 1 is revolved around the engine axis to obtain the 3D grid as shown in Figure 9a. In the integrated model, the external domain is complex because of the presence of the nacelle, pylon external protrusion, wing with high lift surfaces, fuselage and the ground plane. To accommodate the flat, rectangular ground plane and the symmetry plane, the far-field boundaries are defined as a rectangular box. Unstructured 
grid elements are used to discretize the fluid flow region bound by the airframe and far-field external surfaces. A polyhedral density box is defined in the vicinity of the engine to resolve the flow features in the region of interest near the engine. Elements away from the density box are expanded to larger sizes in the far field with an expansion ratio of 1.2. The external far-field grid of the integrated model is shown in Figure $9 \mathrm{~b}$.

The skew angles of the structured grid elements are in the acceptable range of $35^{\circ}-145^{\circ}$ required by the solver. The quality metric of the unstructured elements that measures the deviation of the tetrahedron faces from equilateral triangles is in the acceptable range of 0.4 to 0.6 ( 1 being perfect equilateral triangle faces). This ensures that there is no degenerate low volume fraction skewed tetrahedral elements. The far field external grids are aligned with the bypass nozzle exit face of the internal flow path grids to completely define the discretized integrated and isolated models for flow field solution. Grid Convergence Index (GCI) studies are carried out to finalize the grid size with a GCI index, calculated from Richardson Extrapolation method, of not more than 0.006 for all parameters of interest (Roache, 1993). The finalized overall grid size for the isolated model is $\sim 20$ million elements and for the integrated model is $\sim 65$ million elements.

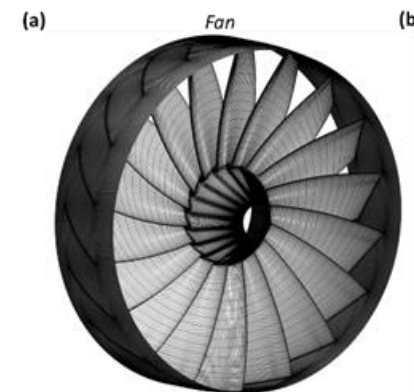

(c)

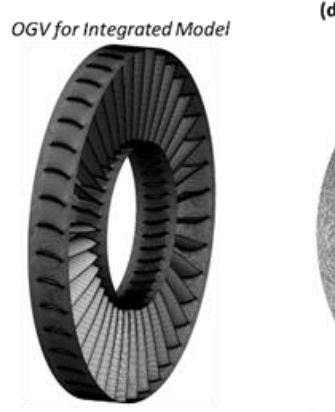

(b)

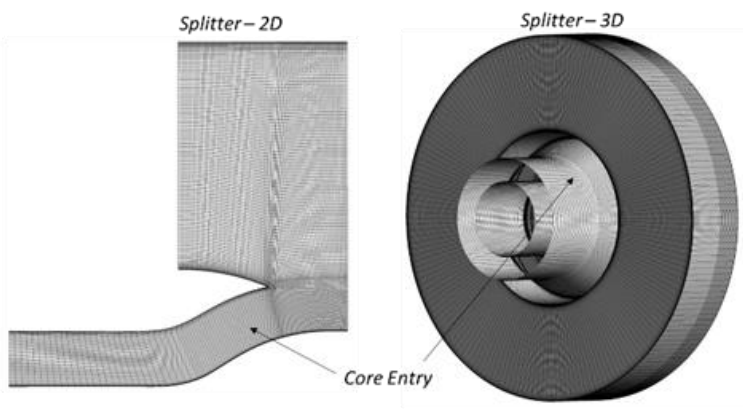

(d)

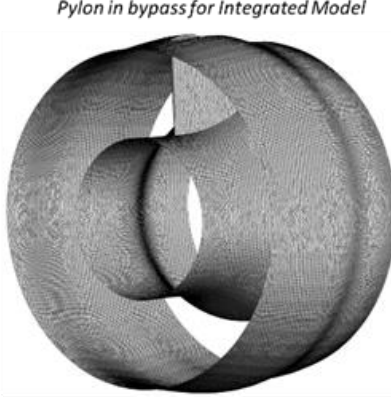

OGV and bypass for Isolated Model

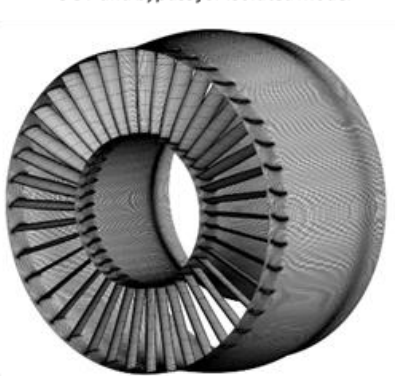

Figure 8 Representative grids of internal flow path components in isolated and integrated models

(a)

Isolated External

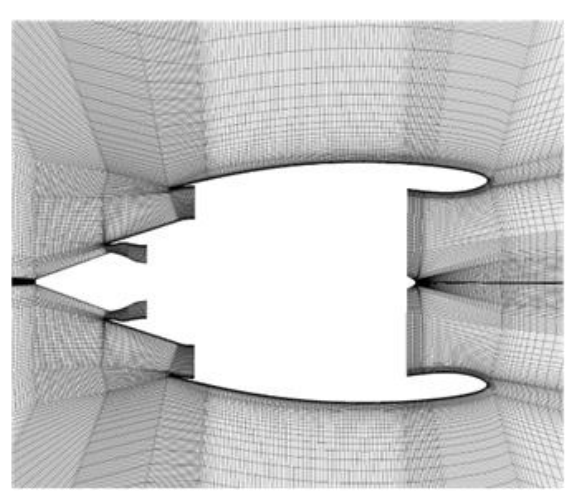

(b)

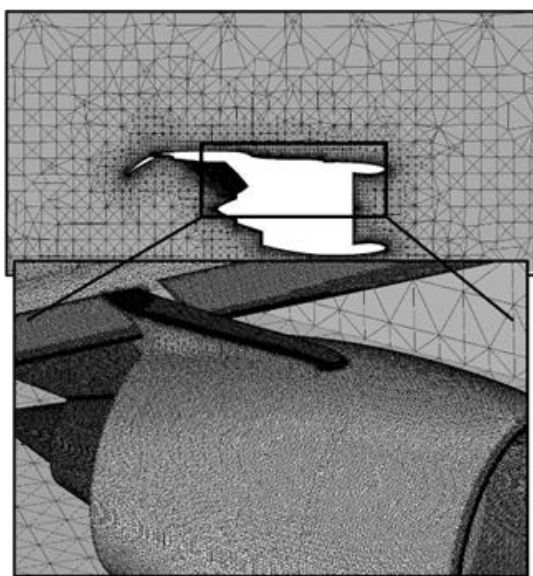

Figure 9 Representative external domain grids - a) Isolated model b) Integrated model

\section{Flow-field Solution}

The flow field solution is obtained using a finite volume based implicit 3D RANS solver, ANSYS CFX. The turbulence closure is modelled using two equation k- $\omega$ Shear Stress Transport (SST) equations because of its ability to capture both the bulk and near wall flow physics appropriately. In both the models, the VPF blade aerofoils are set in the 
reverse thrust mode at a fan rotational speed of $\mathrm{N} \mathrm{rpm}$. The engine operating point is uniquely specified by the fan and core engine parameters. Therefore, a thermodynamic equilibrium analysis is carried out to obtain the flow properties at different core engine stations for the chosen fan operating point. From this, the boundary conditions of the fluid that mimic the core engine is specified at the core inlet and the core exhaust in terms of mass flow rate and total temperature. The flow field is solved for an aircraft landing speed of 80 knots, which is near the middle of typical thrust reverser engagement regime. The free stream velocity at the far field faces is specified as the aircraft landing speed to completely define the flow problem. Additionally, in the integrated model, the ground plane is also specified to move at the landing speed. General Grid Interfaces (GGI) that transfer the computed flux values to different domains are used in the junction between stationary domains. Frozen rotor interfaces that add the effect of domain rotation while retaining the upstream flow profiles are used in the junction between stationary and rotating domains. Figure 10 shows a schematic of the boundary conditions used to obtain the flow solutions in both the integrated and the isolated models.

The computations are carried out using 128 cores of 'DELTA', a High Performance Computing (HPC) facility at Cranfield with a peak processing speed of 60 Tflops. The models are run till parametric convergence criteria are met. The convergence is tracked by tracing the values of mass and momentum fluxes at the engine inlet and outlet faces at each iteration interval. The solution is considered to be converged when the standard deviation of the computed fluxes over 50 iterations is less than $0.2 \%$ of the value at the current iteration. The typical computational time required to obtain converged solution using Message Passing Interface (MPI) parallelization architecture is $\sim 12$ hours for the isolated model and 24 hours for the integrated model.
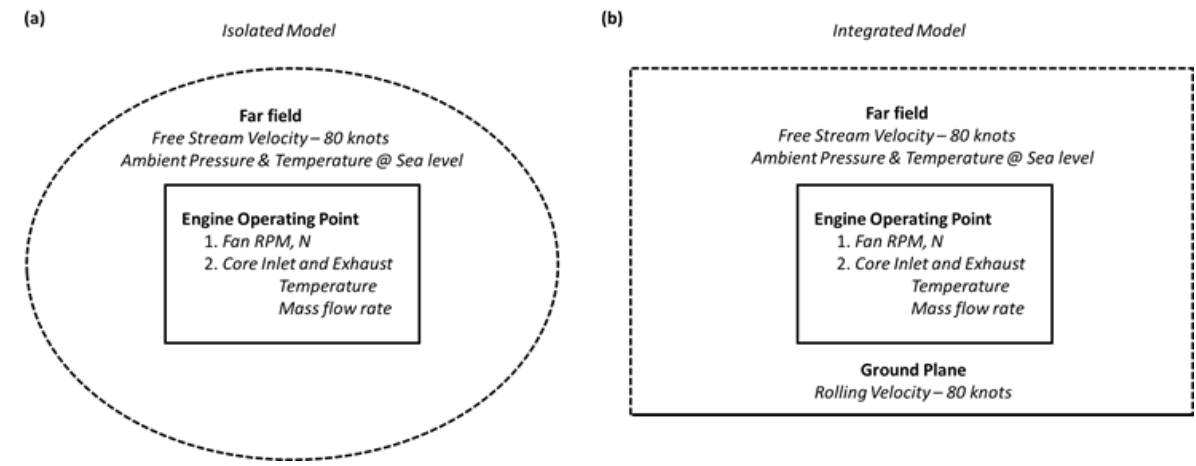

Figure 10 Schematic showing boundary conditions to obtain flow field solution

\section{RESULTS AND DISCUSSIONS}

When the VPF operates in reverse thrust mode the flow enters the engine from the bypass nozzle and exits through the fan inlet plane. This flow is termed as the reverse stream. The development of the reverse stream within the engine flow path components is considered to constitute the internal flow field. The flow behaviour after the reverse stream exits the fan inlet plane and subsequently interacts with the free stream is termed the external flow field. The internal flow field is affected by the external flow field from which the reverse stream originates. Therefore, in this section the comparison of the flow field solution at 80 knots between the isolated research model and the integrated research model is discussed in terms of the differences in: a) the external flow field outside of the engine and b) internal flow field within the engine.

\section{External Flow Field}

The 3D flow streamlines that emanate from the fan inlet plane and develops outside the engine for both models are shown in Figure 11. The general flow behaviour that can be observed from both the models are: 1 . The reverse stream comes out from the fan inlet plane at a swirl angle because of fan rotation and the blade aerofoil angle. 2. The reverse stream occupies the outer annular region near the casing while the inner annulus is occupied by the free stream flow that penetrates into the nacelle, as depicted by the central hollow region in the fan inlet plane. This free stream flow is then turned back to join the reverse stream. 3. As the reverse stream reaches the nacelle lip, it is washed down by the far field free stream flow towards the bypass nozzle exit. 4. As the washed down flow reaches the bypass nozzle exit, it comes under the influence of fan suction and turns $180^{\circ}$ to enter into the engine. Even though both models are able to predict the general flow behaviour, significant differences are observed in the flow parameters which can be highlighted by studying the velocity contours and vectors plotted at three perpendicular planes along the length of the engine as shown in Figure 12. In the Figure 12, Plane 1 is just outside the nacelle lip, Plane 2 is at the fan inlet and Plane 3 is just outside the bypass nozzle exit. The differences that can be observed are:

1. The amount of reverse stream exiting out from the fan is larger in the isolated model. This can be observed in the velocity contours at Planes 1 and 2 where the white region indicates the reverse stream and the blue region is at the free stream velocity. In Plane 1, this is evidenced by the larger thickness of reverse stream ring. In Plane 2, the larger extent 
occupied by the reverse stream is evident both within the nacelle and outside the nacelle where the nacelle is identified by the black ring.

2. The momentum of the reverse stream is higher in the isolated model. This can be observed by the larger length of the velocity vectors plotted in Planes 1 and 2.

3. The presence of the pylon in Plane 3 of the integrated model blocks the development of the flow washed down from the nacelle towards the exit before it turns back into the engine. This blockage results in an accumulation of flow towards the outboard side of the wing because of the clockwise rotational sense (same as fan rotation direction) of the flow swirling around the nacelle. This accumulation of flow leads to a circumferential variation at the bypass nozzle exit of the integrated model as compared to the circumferentially uniform flow field in the isolated model as observed in the vector and contour plots.

(a)

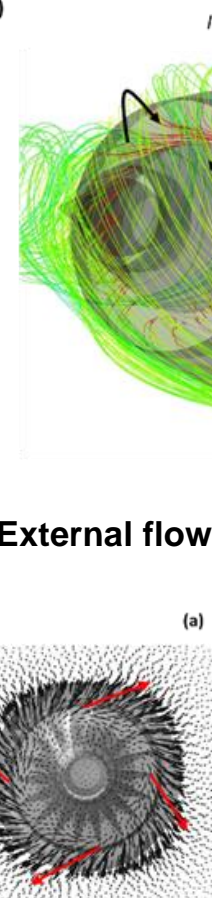

Isolated Model

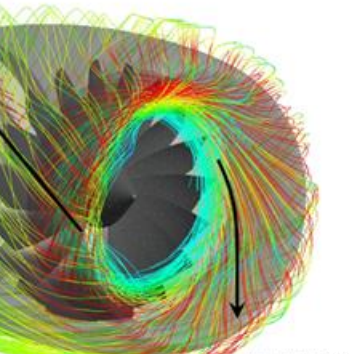

Isolated Model
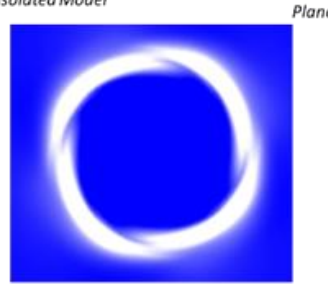

(b)

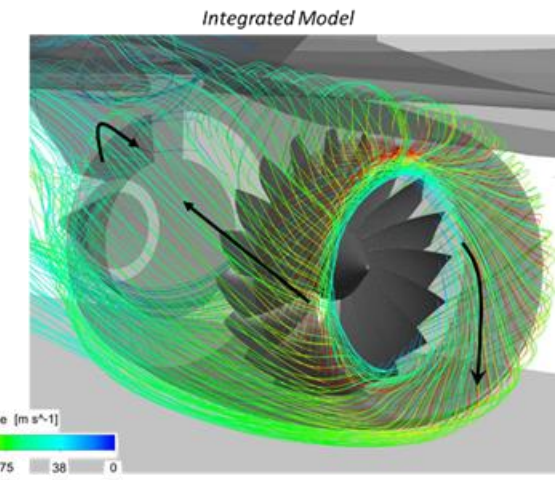

Figure 11 External flow field - 3D flow streamlines: a) Isolated Model b) Integrated Model

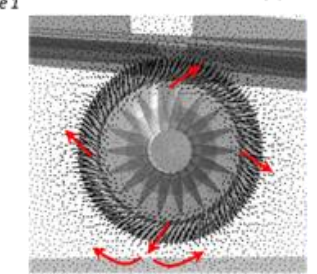

(b)
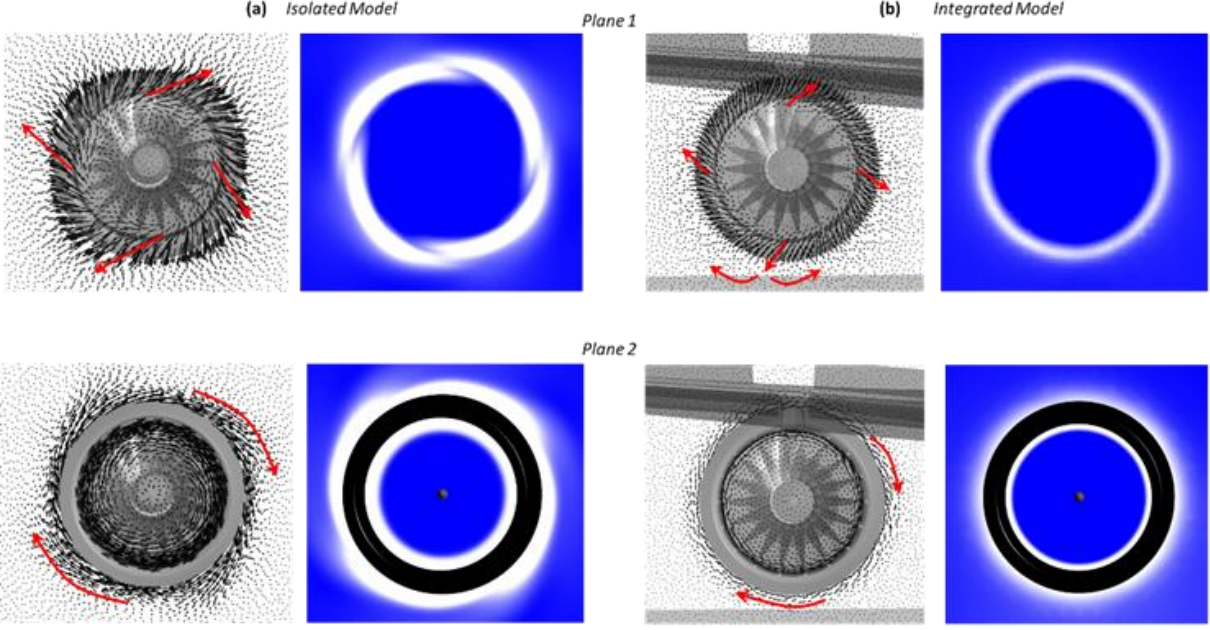

ane 2
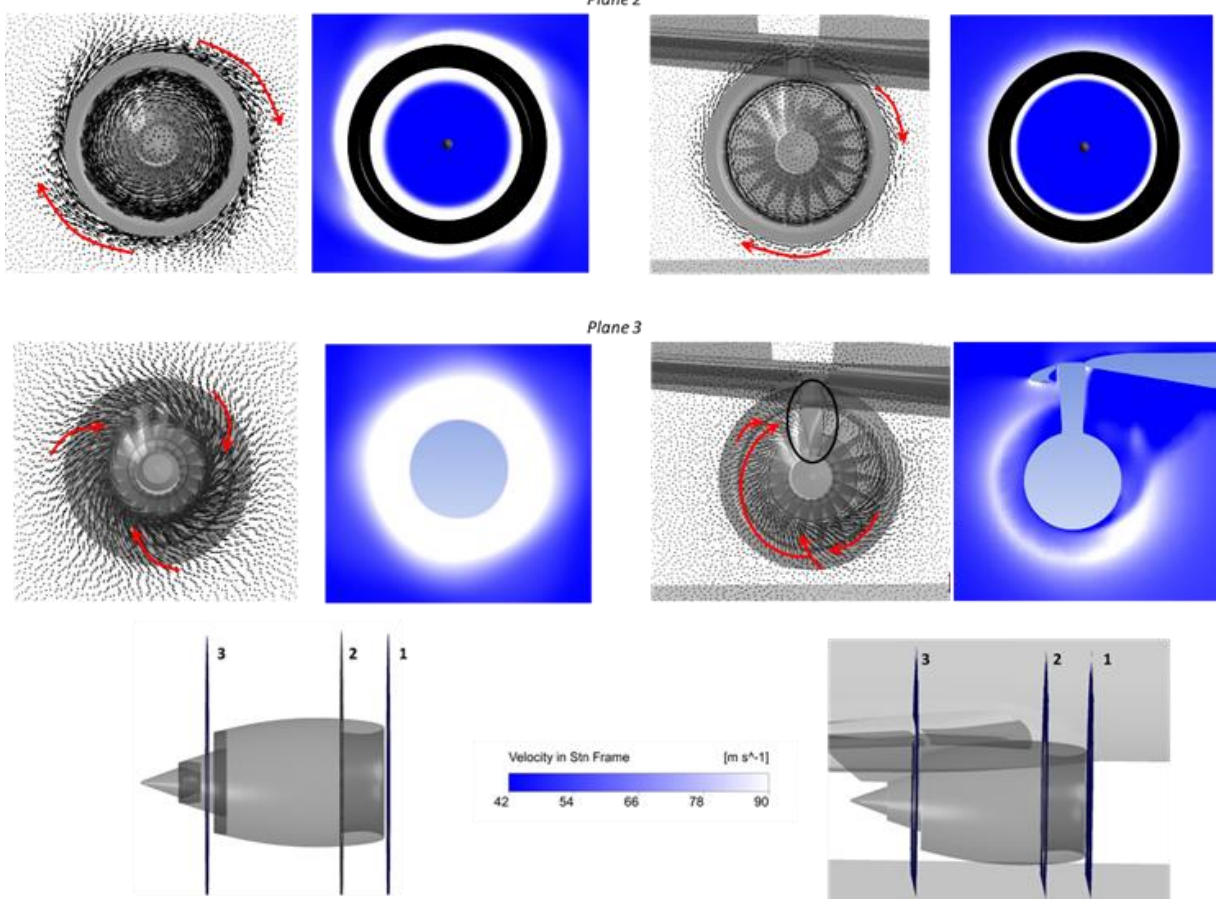

Figure 12 Flow vectors and contours at different planes along the engine length 
The reason for the circumferential variation of the flow at the bypass nozzle exit in the integrated model can be explained by comparing the surface streamlines on a plane extending into the far field at the middle of the engine as shown in Figure 13. In the Figure, from the surface streamline feature marked ' 1 ', it can be observed that in the isolated model, the flow turning $180^{\circ}$ into the engine is similar in the top and bottom portions of the plane. However, at the same mid-location plane in the integrated model, there is no flow entering into the engine at the top surface because of the presence of the pylon. The flow developing along the nacelle trips over the pylon outer surface protrusion and eventually swirls to accumulate on the engine outboard side as seen in the Plane 3 vector plot of Figure 12. In the gap between the engine's bottom surface and the ground plane, the reverse stream washed down towards the bypass nozzle exit and the free stream interact. The profile of the geometric flow path at the bottom of the plane results in a local flow acceleration near the engine's bottom surface that results in further circumferential variations as the flow swirls toward the bypass nozzle as seen in the flow feature marked ' 2 ' in Figure 13. The suction of the fan is operating in a circumferentially varying flow field that has blocked flow regions near the top because of the pylon. This causes the streamlines that escape the fan suction at the bypass exit in the integrated model to be deflected upwards in the direction of the flow between the engine's bottom surface and the ground plane as in the flow feature marked ' 3 '. This net lifting up of the streamlines is not observed in the isolated model where the upward deflection of the flow in the bottom surface is compensated by the downward deflection of the flow from the top surface. The change in the flow behaviour after the streamline lift-up behind the engine affects the pressure distribution on the wing with the high lift devices and spoilers deployed. The differences in the circumferential variations at the bypass nozzle exit result in the net mass flow entering the engine in the isolated model to be over-predicted by nearly $74 \%$. This difference in the circumferential distribution of flow parameters at the bypass exit leads to further differences in the development of the internal flow as explained in the next section.

(a) Isolated Model

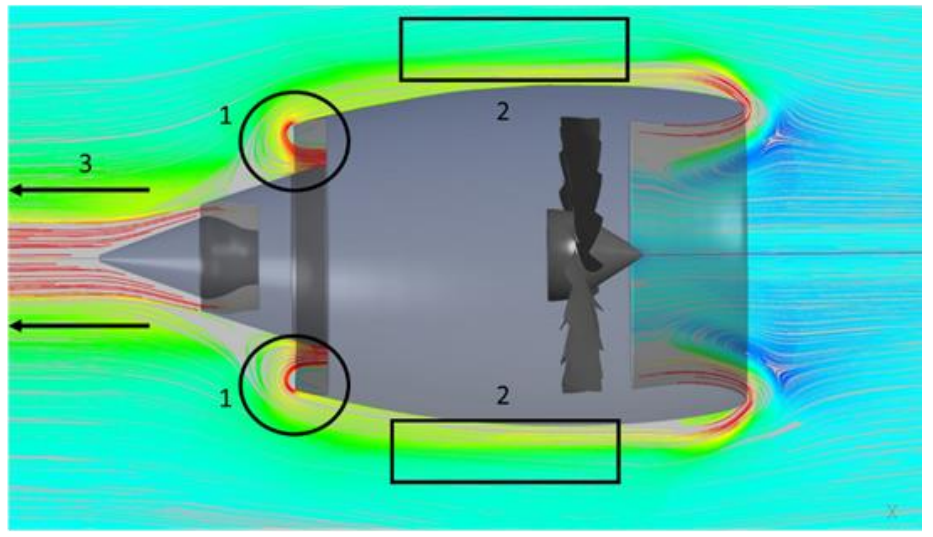

(b) Integrated Model

Volocity in Stin Frame $[m, n-1]$ $150 \quad 113 \quad 75 \quad 38$

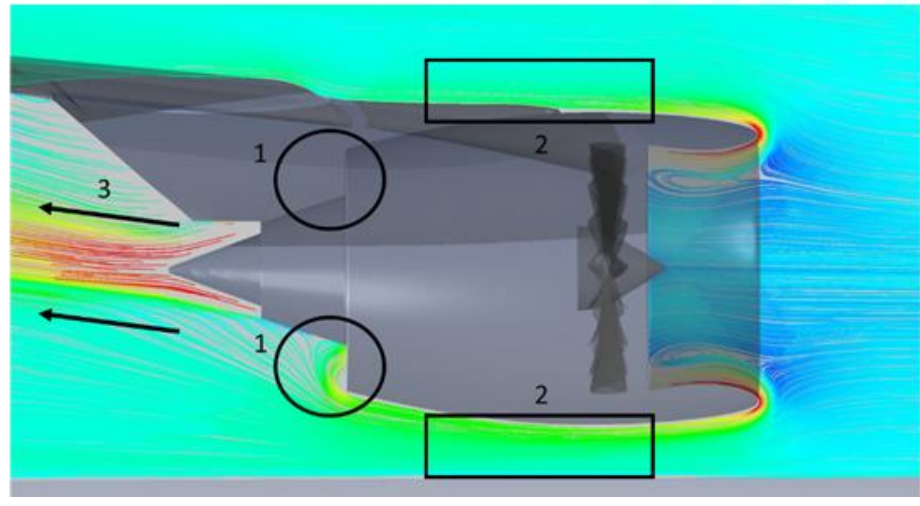

Figure 13 External surface streamlines on mid-engine plane

\section{Internal Flow Field}

The general flow field inside the engine for both models is shown using surface vector plots on a top to bottom midengine plane in Figure 14. In both cases, the development of the internal flow within the engine can be described by:

1. The reverse stream that is established from the bypass nozzle exit flows towards the fan. (Red straight arrow) 
2. A part of this reverse stream turns $180^{\circ}$ at the splitter edge into the core engine and the remaining part enters the fan passages where it meets the free stream that penetrates in from the inlet. (Red branching arrows)

3. The flow is deflected radially outwards in the fan passages, and one part of it escapes to establish the reverse stream that exits at the fan inlet and the other part is turned back into the engine towards the OGV.

4. The escaping reverse stream entrains the free stream flow and causes it to turn back on to itself and join the reverse stream. (Blue arrow)

5. The flow turned back towards the OGV loses its momentum as it passes through the OGV passages and re-joins the reverse stream. (Green arrows) ovals)

6. There are separation bubbles at the bypass nozzle lip and the splitter edge because of the $180^{\circ}$ flow turning (Black

(a)

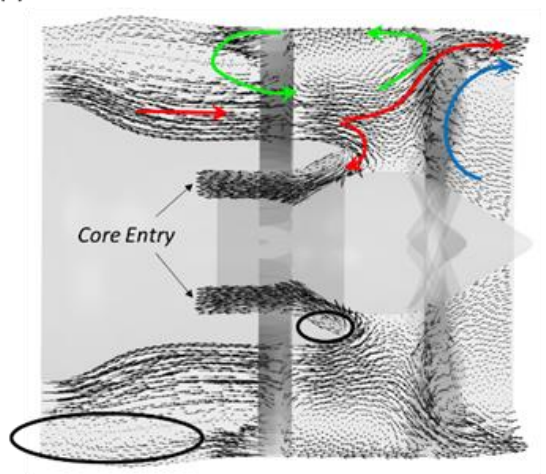

$\longrightarrow$ Reverse stream

Isolated Mode

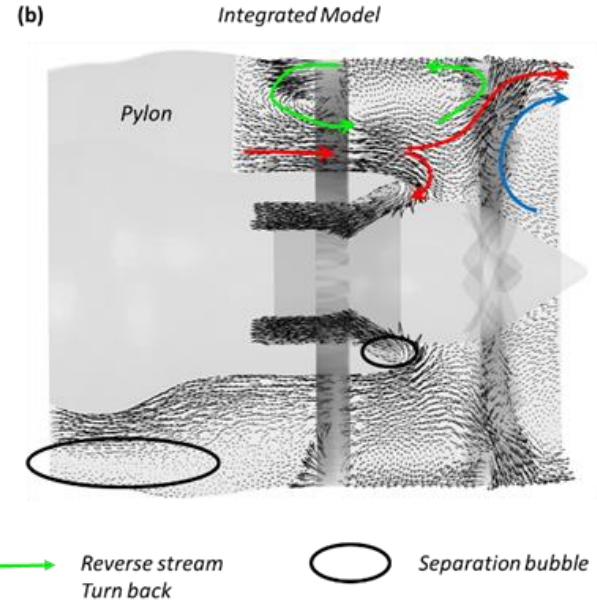

Figure 14 Internal surface streamlines on engine mid-plane

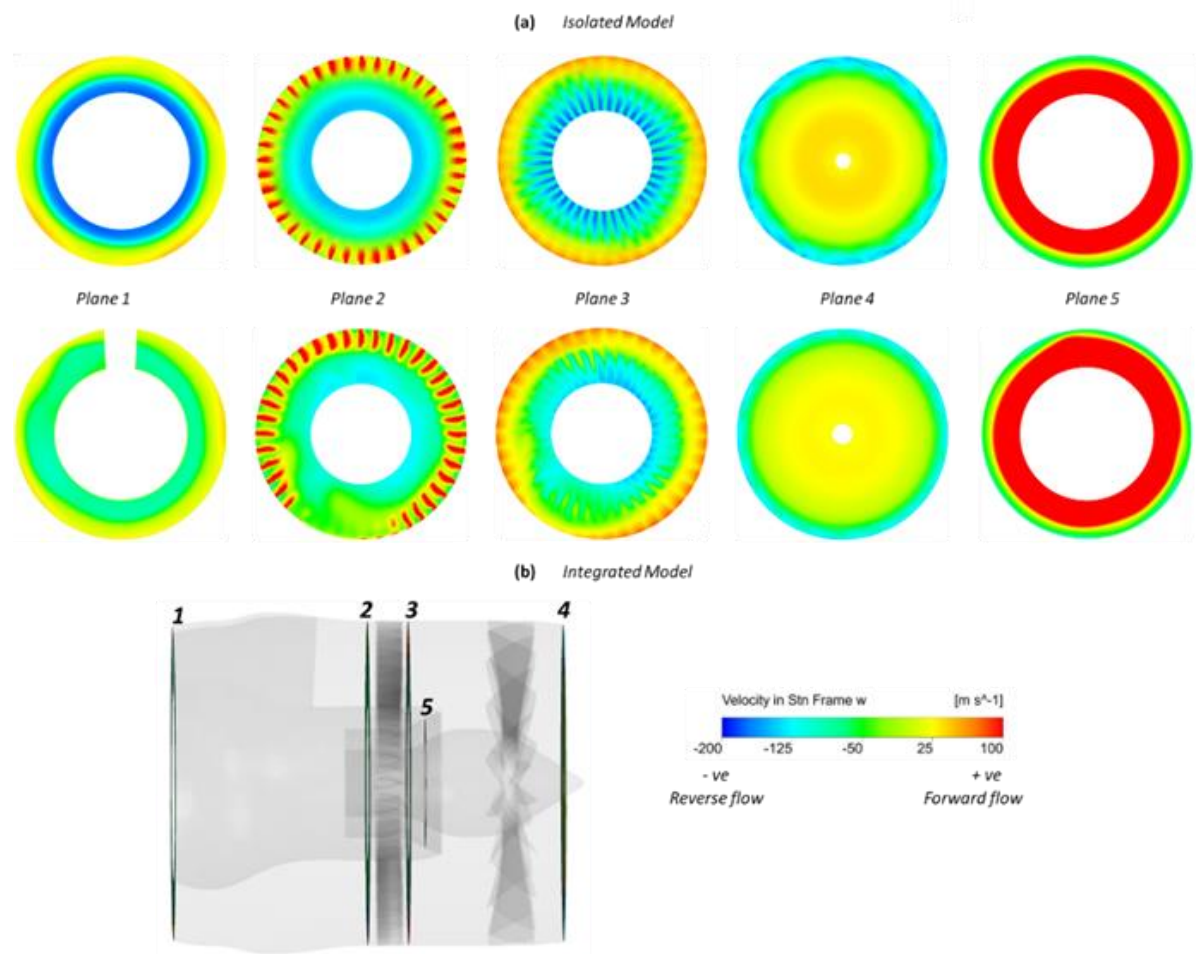

Figure 15 Internal flow velocity contours at different stream-wise locations

The specific details of the internal flow development within the engine are different between the models because of:

1. The circumferential variation in the external flow field from which the reverse stream develops.

2. The development of the reverse stream through the pylon strut in the engine flow path leaves a wake signature and affects the flow angles. 
The differences in the details can be studied by comparing the flow velocity contours at different stream-wise locations along the engine length as shown in Figure 15. The stream-wise locations chosen to show the differences are Plane 1: Bypass nozzle outlet, Plane 2: OGV outlet, Plane 3: OGV inlet, Plane 4: Fan inlet and Plane 5: Core engine inlet. The dimensions of the Plane 5 in the image is scaled to the same size as the other Planes for illustration purposes. The major difference between the models is the significant circumferential non-uniformity observed in each plane of the integrated model as compared to the isolated model.

Further, the following observations can be made from comparing the flow contours between the models:

1. The flow entering the engine at Plane 1 is circumferentially uniform in the isolated model. However, in the integrated model, the flow is non-axisymmetric because of the circumferential variation in the flow field at the engine exit caused due to flow accumulation in the wing outboard side.

2. The flow in Plane 2 is bi-directional with the outer annulus occupied by the flow turned back from the fan and the inner annulus occupied by the reverse stream. The wake signature from the passage of the turned back flow through the OGV blades is apparent in the outer annulus of both the models. This wake signature is uniform around the annulus in the isolated case. However, in the integrated case, the pylon wake interacts with the turned back OGV wake resulting in a sector of sluggish flow that is convected downstream. In addition to this, the reverse stream towards the fan in the integrated model is also circumferentially non uniform because of the non-uniformity convected downstream from Plane 1.

3. The outer red ring in Plane 3 indicates the turned back flow from the fan before entering the OGV passages. The turned back flow is larger in the case of the integrated model because the free stream penetrates further into the fan passages and causes a larger proportion of the low momentum reverse stream to be turned back.

4. In Plane 4, the reverse stream flowing out of the fan occupies the outer annulus and the free stream flowing into the fan occupies the inner annulus. In both the models, the outer portions exhibit fan wake signature while the inner portion is uniform. The larger amount occupied by the reverse stream is apparent in the isolated model.

5. Plane 5 indicates the profile of the flow that is entering the core engine. The outer annular green portion indicates the separated region because of the flow turning into the core engine. This separated region extends to a larger radial extent in the isolated model. The integrated model shows a larger amount of circumferential flow non-uniformity with a more pronounced separation in a sector of the same size occupied by the pylon.

In addition to the differences in the flow velocity magnitudes as observed in the contour plots, the direction of the velocity vectors as the flow develops in the engine is also different. These differences are shown in Figure 16 as the comparison of circumferentially averaged absolute flow angles between the models in the five Planes as in Figure 15. In the plots at all planes, there is a sharp change in the sign of the flow angle at some spanwise location. This discontinuity represents the change in the direction of the flow. At Plane 1, the inner annulus with negative flow angle represents the reverse stream, while the outer annulus represents the separation at the bypass nozzle lip. The inner annulus in Planes 2 , 3 and the outer annulus in Plane 4 is occupied by the reverse stream. The outer annulus of Planes 2,3 is the turned back flow that is directed in the nominal forward flow direction, and the inner annulus of Plane 4 indicates the free stream in the forward direction that enters in through the nacelle. At Plane 5, the flow has turned $180^{\circ}$ at the splitter edge to feed the core engine and is pointing at the nominal forward direction in the inner annulus. The discontinuity in the flow angle at Plane 5 represents the separation bubble at the splitter edge lip. The differences observed from the flow angle plots are:

1. At Plane 1, the isolated model predicts the flow to enter at a larger angle because there is no pylon to block and direct the flow as in the integrated model. The larger amount of reverse stream in the isolated model can be identified by the location of the flow angle discontinuity at $\sim 0.65$ span as compared to $\sim 0.55$ span in the integrated model.

2. At Plane 2, the average angle at the outer annulus occupied by the turned back flow is larger in the isolated model. This is because the average angle in the integrated model is reduced by the pylon wake. In the inner annulus, the flow angle in the integrated model is fairly constant because the flow is directed by the pylon.

3. At Plane 3, the flow angles are similar for both the models because: a) the flow in the inner annulus in both cases has passed through the OGV and is at the OGV inlet angle. b) The flow in the outer annulus that has turned back from fan passages is at the fan blade outlet angle.

4. At Plane 4, the flow angle trends are similar because the flow that has passed through the fan aerofoils is affected by the domain rotation and blade inlet angle. Minor differences in the span-wise distribution exist because of the differing momenta of the reverse stream that drives the interaction within the fan passages.

5. At Plane 5, the angle of the flow entering the core engine is similar in both cases, because the stream follows the OGV aerofoil inlet angle. However, there is a larger region of separated flow in the isolated model because of the higher momentum of the stream that turns back at the splitter edge. 

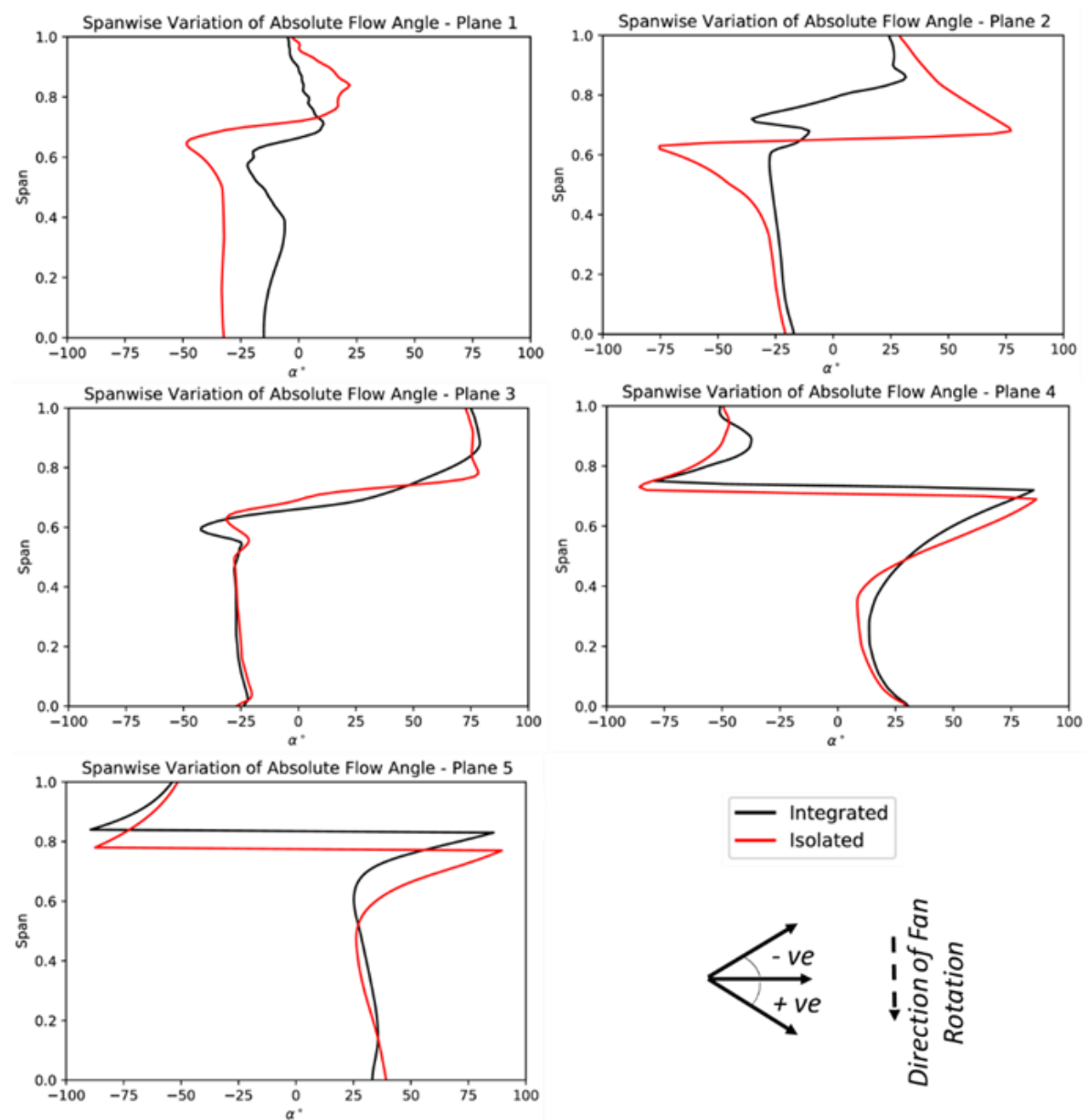

Figure 16 Comparison of spanwise variation of flow angles for isolated and integrated models

\section{Significance of Differences in Flow Field}

The differences in the external and internal flow field affect the computed parameters that are required in the design of a VPF system to generate reverse thrust. There are two major parameters of interest that need to be computed from the flow field solution: 1. Amount of reverse thrust generated. 2. Distortion levels transferred into the core engine. It is apparent from the reported differences that the values of each of these parameters will be affected. The reverse thrust is estimated from a momentum balance across the engine faces. The circumferential and radial distortion indices of the total pressure for the flow entering the core engine are computed using the standard formulations specified by Aerospace Information Report 1419 and Aerospace Recommended Practise 1420 (SAE, 1999; SAE, 2002). The differences in the computed values of the reverse thrust, Circumferential Distortion Index (CDI) and Radial Distortion Index (RDI) for the isolated model are shown in Table 2. The reverse thrust is overestimated in the isolated model because the amount of mass flow sucked in from the bypass nozzle exit is larger than the integrated model. The distortion levels of the flow entering the core engine depends on the circumferential and radial non-uniformity of the flow. The circumferentially uniform flow field in the isolated model causes the circumferential distortion indices to be under-predicted. The turning of higher momentum reverse stream into the core engine in the isolated model results in a larger radial separation at the core engine entry. This larger separation causes the radial distortion indices to be over-predicted.

\section{Table 2}

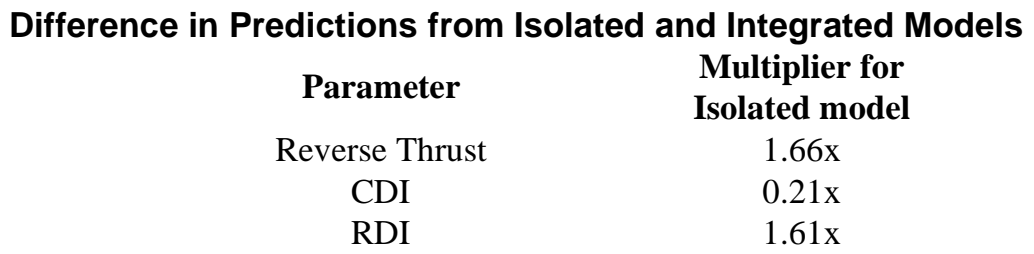

It is also to be noted that even though the isolated model is able to capture the general flow behaviour within the engine except for the circumferential non-uniformities, it cannot properly account for the changes in the external flow field behind the engine like the net lift up of streamlines. This flow behind the engine influences the pressure distribution in the airframe surfaces. Therefore, proper resolution of the flow field around the entire aircraft is only possible with the integrated model. It is only with the availability of such true representation of the general aircraft flow field that values of 
other important aircraft landing design parameters such as drag increment because of thrust reverser engagement, airframe forces and control surface deflections required can be estimated.

\section{CONCLUSIONS}

The research model development rationale for studying the feasibility of using VPF for generating reverse thrust in modern ultra-high bypass ratio turbofan engines is explored by comparing the flow field solution obtained from an isolated engine model and an engine model integrated with the airframe in landing configuration. It is observed from the flow field solution that even though the isolated model is able to predict the general flow behaviour when the VPF is operating in reverse thrust, there are significant differences in specific details of the flow development. The isolated model over-predicts the amount of mass flow in the reverse stream by $74 \%$ because the effect that the pylon and the ground plane introduce on the flow parameters at the engine exit is not resolved. This increase in the predicted reverse stream mass flow results in the computed reverse thrust to be over-predicted by $66 \%$. The increased momentum of the reverse stream in the isolated model also leads to the RDI into the core engine to be over-predicted by $61 \%$. The flow field predicted by the isolated model does not indicate circumferential variation of flow properties because of the lack of proper resolution of the external flow field, development of the internal flow past the pylon and the large pylon wake signature as in the integrated model. This results in an inappropriate representation of the circumferential flow distortion entering into the core engine resulting in the CDI value to be under-predicted by $79 \%$. In addition to this, the isolated model is unable to provide any information on the flow field over the portions of the aircraft behind the engine, when the engine is operating in a manner that is significantly different from nominal operation.

This inadequate representation of the VPF reverse thrust flow field, both internal and external to the engine, as obtained from the isolated model is misleading in terms of the key design parameters like the amount of reverse thrust and the distortion levels that need to be handled by the core engine. Thus, using an isolated model for making engineering decisions in the design of VPF system can be detrimental in the process of engine and aircraft design optimization. Therefore, it is recommended that any VPF design for reverse thrust be qualified for its suitability in the aircraft by using an integrated research model that explicitly includes the whole engine, nacelle, pylon, wing and airframe and provides a realistic flow field description.

\section{NOMENCLATURE}

$\begin{array}{ll}\text { ADP } & \text { Advanced Ducted Propulsor } \\ \text { FLA } & \text { Forward Looking Aft } \\ \text { GCI } & \text { Grid Convergence Index } \\ \text { GGI } & \text { General Grid Interface } \\ \text { MPI } & \text { Message Passing Interface } \\ \text { OGV } & \text { Outlet Guide Vane } \\ \text { QCSEE } & \text { Quiet Clean Short-haul Experimental Engine } \\ \text { RANS } & \text { Reynolds Averaged Navier Stokes } \\ \text { SST } & \text { Shear Stress Transport } \\ \text { VPF } & \text { Variable Pitch Fan }\end{array}$

\section{Symbols}

$\mathrm{k}$

$\mathrm{N}$

$\alpha$

$\omega$

\author{
Turbulence kinetic energy \\ Fan rotational speed \\ Absolute flow angle \\ Turbulence eddy frequency
}

\section{ACKNOWLEDGMENTS}

The authors are grateful to Mr John Whurr of Rolls-Royce plc. for continuous support and review in the development of the research model. The research is supported and published with permission from Rolls-Royce plc.

\section{References}

Bentley, D. (2018). Reverse thrust aerodynamics of ultra-high bypass variable pitch turbofans. PhD. Cranfield University.

Denning, R.M., (1972). Variable Pitch Ducted Fans for STOL Transport Aircraft. In ASME 1972 International Gas Turbine and Fluids Engineering Conference and Products Show. American Society of Mechanical Engineers Digital Collection.

Halliwell, I. and Justice, K., (2012). Fuel Burn Benefits of a Variable-Pitch Geared Fan Engine. In 48th AIAA/ASME/SAE/ASEE Joint Propulsion Conference \& Exhibit (p. 3912). 
Hamilton, G.L. and Welge, H.R., (1992). Civil Aircraft Challenges in Engine/Airframe Integration. In ASME 1992 International Gas Turbine and Aeroengine Congress and Exposition. American Society of Mechanical Engineers Digital Collection.

Krishnan, G., Perullo, C. and Mavris, D.N., (2013). An Assessment of Relative Technology Benefits of a Variable Pitch Fan and Variable Area Nozzle. In 49th AIAA/ASME/SAE/ASEE Joint PropulsionConference (p. 3604).

Lolis, P., Giannakakis, P., Sethi, V., Jackson, A.J.B. and Pilidis, P., (2014). Evaluation of aero gas turbine preliminary weight estimation methods. The Aeronautical Journal, 118(1204), pp.625-641.

Mazzawy, R.S., (2010), October. Performance Study for the Benefits of a Variable Pitch Composite Fan. In ASME Turbo Expo 2010: Power for Land, Sea, and Air (pp. 37-45). American Society of Mechanical Engineers Digital Collection.

Moore, R.D., (1979). Aerodynamic performance of 1.38-pressure-ratio, variable-pitch fan stage. NASA.

Mourouzidis, C. (2016). Cycle Optimization \& Preliminary Design of Very Low Specific Thrust Turbofan Engines. PhD. Cranfield University.

Rajendran, D.J. and Pachidis, V., (2019). Fan Flow Field in an Installed Variable Pitch Fan Operating in Reverse Thrust for a Range of Aircraft Landing Speeds. Journal of Engineering for Gas Turbines and Power, 141(10).

Reemsnyder, D.C. and Sagerser, D.A., (1979). Reverse Thrust Performance of a Variable-Pitch Fan Engine at Forward Velocity. Journal of Aircraft, 16(12), pp.848-855.

Roache, P.J., (1993). A method for uniform reporting of grid refinement studies. ASME-PUBLICATIONS-FED, 158, pp.109-109.

S.A.E., AIR1419, (1999). Inlet Total-Pressure-Distortion Considerations for Gas-Turbine Engines.

S.A.E., ARP1420, (2002). Gas Turbine Engine Inlet Flow Distortion Guidelines.

Samanich, N.E., Reemsnyder, D.C. and Bloomer, H.E., (1980). Reverse thrust performance of the QCSEE variable pitch turbofan engine. SAE Transactions, pp.3623-3650.

Schaefer, J.W., Sagerser, D.R. and Stakolich, E.G., (1977). Dynamics of high-bypass-engine thrust reversal using a variable-pitch fan.

Templalexis, I., Pilidis, P., Pachidis, V. and Kotsiopoulos, P., (2006), January. Quasi-three-dimensional compressor performance simulation using streamline curvature and multi-parallel compressor theory. In ASME Turbo Expo 2006: Power for Land, Sea, and Air (pp. 297-309). American Society of Mechanical Engineers Digital Collection.

Tweedt, D.L., (2014). Computational aerodynamic simulations of an $840 \mathrm{ft} / \mathrm{sec}$ tip speed advanced ducted propulsor fan system model for acoustic methods assessment and development.

Williams, T.S. and Hall, C.A., (2018), January. Reverse Thrust Aerodynamics of Variable Pitch Fans. In ASME Turbo Expo 2018: Turbomachinery Technical Conference and Exposition. American Society of Mechanical Engineers Digital Collection.

Yang, X., Tang, H. and Chen, M., (2018). Performance Modeling and Optimization Assessment of Variable Pitch Fan for Ultrafan Engine. In 2018 Joint Propulsion Conference (p. 4400). 